\title{
Parental Concerns about the Future of Children with Autism: A Qualitative
} Study in Iran

\author{
Research Article
}

\section{Fatemeh Ganjeh1, Masoud Fallahi-Khoshknab2* ${ }^{*}$ Kourosh Zarea ${ }^{3}$, Eesa Mohammadi ${ }^{4}$, Forough Riahi ${ }^{5}$}

\author{
1.PhD Candidate, Nursing Care Research Center in Chronic Diseases, Nursing Department, \\ School of Nursing \& Midwifery, Ahvaz Jundishapur University of Medical Sciences, Ahvaz, Iran. \\ 2.PhD, Full Professor, Nursing Department, \\ University of Social Welfare and Rehabilitation Sciences (USWR), Tehran, Iran. \\ 3. PhD, Associate Professor, Nursing Care Research Center in Chronic Diseases, Nursing Department, \\ School of Nursing \& Midwifery, Ahvaz Jundishapur University of Medical Sciences, Ahvaz, Iran. \\ 4.PhD, Full Professor, Faculty of Medical Sciences, Tarbiat Modares University, Tehran, Iran. \\ 5. MD, Associate Professor, Department of Psychiatry, School of Medicine, \\ Ahvaz Jundishapur University of Medical Sciences, Ahvaz, Iran.
}

\begin{abstract}
Introduction: Regarding the growing trend of autism spectrum disorder, the complex and lifelong nature of it and concerns of parents about the life experience and caring for an autistic child, especially with regard to their future life, to provide a suitable environment for the child to enjoy human rights in life is one of the research priorities in Iran. Therefore, this study aimed to explain parents' experiences in explaining their concerns about the future of the child in life. Materials and Methods: This qualitative study was performed on the parents of autistic children referred to Yas and Nahal rehabilitation centers in Arak and Ahvaz. A total of 8 parents of children with autism were enrolled in the study using purposeful sampling method. Data were collected by semi-structured interviews and field notes and analyzed using MAXQUDA10 software. Results: The results of the data analysis have led to the emergence of three main categories "self-sufficiency and independency in life", "transition to adolescence" and "child education and learning", which outlines the different dimensions of parental concern related to the child in the future life. Discussion and Conclusion: Based on the results of this study, designing, organizing and implementing effective and efficient interventions in educational, therapeutic, rehabilitation, welfare, legal and social areas appropriate to the developmental stages of the child, with the aim of responding to the needs of people with autism spectrum disorders and their families are increasingly needed in the successful transition to the adulthood and maintaining and promoting their well-being.
\end{abstract}

Key Words: Autism Spectrum Disorder, Children, Future, Iran, Parental Concern, Qualitative Research.

\section{Introduction}

Presence of an autistic child in a family is a difficult experience for parents and family(1) because it brings many responsibilities and concerns in different aspects ranging from care, treatment, education to financial, occupational and social wellbeing(2). Parents of autistic children experience higher levels of stress in life than parents of children with developmental disabilities and children with normal development(3-6). Such families confront an accumulation of needs in the life and care of their autistic child(7) that will lead to

\section{* Corresponding Author:}

\section{Masoud Fallahi-Khoshknab}

Nursing Department,

University of Social Welfare and Rehabilitation Sciences (USWR),

Koodakyar St., Daneshjo Blvd, Evin, Tehran, Iran.

Zip Code: 1985713834.

Email Id: fallahi@uswr.ac.ir,msflir@yahoo.com worry-filled thoughts(8). There are various factors that contribute to the parents' stress, including concerns about the experience of caring for a child with a disability(9).

Concern in the concept of cognitive process is defined as a chain of negative and relatively uncontrollable thoughts and perceptions, and represents an ongoing attempt to engage in solving a subjective problem with an unknown outcome and possibly with one or more outcomes that are negative(10). Concern is generally described as anxiety or fear of the future(11). In the study by Agston et al. (2011), concerns about the future of the child are one of the major parental concerns(10). Adaptability of the child in future in the areas of health, education, employment, financial, marriage, and social participation have been parents' concerns about the child's future(11) . In fact, concern about the future refers to a repetitive thinking about the potentially unpleasant consequences of future events that the chronic nature of the disorder and its adverse 
effect on child development are the major cause of such experiences in parents(12).

Parental concern on the one hand can lead to readiness for decision making, action and arousal at adaptive levels and can help solve the problem. On the other hand, it is a pathological anxiety and is associated with an increased risk of anxiety and depression due to feelings of fear and helplessness $(8,12)$. According to some evidence, mothers' concerns have affected their performance in stressful situations and have reduced their ability to respond effectively to their owns and their children's needs(13). The excessive concern of a parent of a child with disability is not only an obstacle to fullfill the needs of the affected child, but also affects fullfilling the needs of other children, marital and professional life needs(8).

Available evidences suggest that professionals are more focused on interventions in relation to autistic children and do not fully understand family concerns and priorities(9). Most autism-related researches have focused on genetic factors, characteristics, treatment, and outcomes of these children(2), and there are fewer studies on the experiences of parents and their need for effective support and interventions during their lives(14). Therefore, regarding the increasing trend of autism and the complex and chronic nature of it and its impact on the family and their concerns about the future life of the child, and emphasis on the family-centered approach to growth-related care in health services(15) with focusing on the cultural context in studies of the family with an autistic member(16), plus the role of qualitative research as a naturalistic and valuable approach to explain the meaning and experience of the subjective and profound and complex experiences(17). Accordingly, this study was aimed to find parents' experiences of concerns about the autistic child' future in life.

\section{Materials and Methods}

The present qualitative study was carried out using content analysis approach. The study population consisted of all parents of children with autism living in the cities of Arak and Ahvaz in Iran, who experienced living with those children. The research setting included Yas and Nahal Rehabilitation Centers in Arak and Ahvaz. The research samples were selected from parents of children with autism referred to the above centers. The inclusion criteria were diagnosis of ASD according to the medical records, children had to be diagnosed with ASD for at least 1 year and that the child should not have intellectual disability. Attempts were made to maximize the diversity of the population selected in terms of (education, age, gender, duration child's disorder etc.). The purposeful sampling was performed on the parents of children with autism referring to the research setting. This continued until the data saturation was met until all the codes and categories were finalized, and made sure that there is no more information requiring a new code or changing of existing codes. For this purpose, theoretical sampling was used to develop the features of categories and to complete their dimensions. Thus, eight parents of children with autism as main caregivers were selected. The main data collection instrument was a semistructured face to face interview that took place at a right time and place agreed upon by the parents. Field notes were also used to access information that was not available through interview. Based on parents' preference the interviews took place either at parents' home, or at the Rehab Center. All interviews were conducted by the first author, audio recorded with the consent of participants and transcribed for analysis. The interviews lasted for 70 to 130 minutes. The interview initially began with a general open question: "How would you describe your life since child's problem started?" Then, based on the experiences expressed, keeping the purpose of the study in mind, follow up questions such as: what did you mean by that? How? When? and Who? Were asked to get more information related to the study and to clarify the various dimensions of the issue. In some cases, it was necessary to conduct supplementary interviews another appropriate time as agreed by both parties. All of their non-verbal behaviors, like facial and emotional expressions, were observed and recorded.

Qualitative content analysis method was used in this research to analyze the data in order to achieve the obvious and hidden content of the data and concepts with different abstraction levels(18).Data analysis was performed along with the data collection using MAXQUDA 10 software. All recorded contents were typed word-for-word at the end of each interview session. Notes were prepared at the end of each interview or in the field of research. Interview transcripts along with the field notes were reviewed several times to reach a general understanding of its contents and later was broken to the codes. The primary codes were compared with each other and similar codes were put in sub-categories. Main categories were formed based on continually comparing the subcategories and their similarities and contents.

To achieve the accuracy and trustworthiness of data, four criteria proposed by Guba and Lincoln were used(18). The researcher attempted to ensure the data creditability by performing purposeful sampling method with a diverse participant papulation, collecting data using interview method and field notes, allocating sufficient time for data collection and analysis, and review seasons with participants and colleagues. The research team members helped to improve the dependability of findings by providing evidence-based results (quotes) and reviewing of all paths of study. In order to achieve conformability and objective and nonbiased data, the researchers tried not to let their assumptions during data collection and analysis phases as much as possible. The analyzed data were also reviewed by both participants and members of the research team. Utilizing the external check method, a number of coded and categorized interviews were provided to the university professors who were familiar with the study and the qualitative research method, so that they could investigate the correctness of the coding process. The researchers attempted to describe participants' characteristics, challenges and limitations 
and to learn from the experiences of the beneficiaries and ASD experts as well as participants at the "National Autism Conference" and also by selecting participants from the two cities of Ahvaz and Arak to meet the transferability criterion and to be able to use the findings in other contexts. The researchers obtained permission from ethics committee of Ahvaz Jundishapur university of medical sciences, as well as the welfare and rehabilitation organizations of Arak and Ahvaz. In all stages of research confidentiality was respected, written consent was obtained and incentives provided to participant to appreciate their participation.
This study was aimed to find parents' experiences of concerns about the autistic child's future in life. After analysis of data three main themes of "selfsufficiency and independency in life", "transition to adolescence", and "child education and learning" were extracted. The demographic characteristics of the participants are presented in Tables 1 and 2, and main and sub-categories are presented in Table 3 . The present results showed the dimensions of parental concerns about the future of autistic children in their lives and in responding to their needs, the details of which are as follows:

\section{Results}

Table1: Demographic characteristics of participants

\begin{tabular}{|c|c|c|c|c|c|c|c|}
\hline $\begin{array}{l}\text { Particip } \\
\text { ants }\end{array}$ & $\begin{array}{c}\text { Family } \\
\text { relationship } \\
\text { with the child }\end{array}$ & $\begin{array}{c}\text { Participants' } \\
\text { age }\end{array}$ & $\begin{array}{l}\text { Child's } \\
\text { age }\end{array}$ & $\begin{array}{c}\text { Level of } \\
\text { Education }\end{array}$ & Job & $\begin{array}{l}\text { Number of children / } \\
\text { gender and child birth } \\
\text { rank }\end{array}$ & City \\
\hline $\mathrm{P} 1$ & Mother & 29 & 4.5 & Diploma & Housewife & 1 (son) & Arak \\
\hline $\mathrm{P} 2$ & Father & 36 & 4.5 & Diploma & Self-employed & 1 (son) & Arak \\
\hline $\mathrm{P} 3$ & Mother & 26 & 6 & Diploma & Housewife & 1 (son) & Arak \\
\hline $\mathrm{P} 4$ & Father & 29 & 6 & Diploma & Self-employed & 1 (son) & Arak \\
\hline P5 & Father & 46 & 6 & Middle school & $\begin{array}{l}\text { Manual } \\
\text { worker }\end{array}$ & 3 (Third child, son) & Ahvaz \\
\hline P6 & Mother & 40 & 6 & Middle school & Housewife & 3 (Third child, son) & Ahvaz \\
\hline P7 & Mother & 27 & 7 & Associate Degree & Housewife & 2 (Second child, boy) & Arak \\
\hline P8 & Mother & 29 & 10 & MS & $\begin{array}{l}\text { Occupational } \\
\text { therapist }\end{array}$ & 2 (First child, daughter) & Arak \\
\hline
\end{tabular}

Table2: Demographic characteristics of participants

\begin{tabular}{|c|c|c|c|c|c|c|c|c|c|c|c|c|c|}
\hline $\begin{array}{l}\text { Number of } \\
\text { participants }\end{array}$ & $\begin{array}{l}\text { Average age } \\
\text { of } \\
\text { participants }\end{array}$ & $\begin{array}{c}\text { Average } \\
\text { child's } \\
\text { age }\end{array}$ & $\begin{array}{r}\text { Famil } \\
\text { relations } \\
\text { with the } \\
\text { (parent }\end{array}$ & & $\begin{array}{r}\text { Level o } \\
\text { educatio }\end{array}$ & & Job statu & & $\begin{array}{l}\text { Number } \\
\text { childre }\end{array}$ & & $\begin{array}{l}\text { Child } \\
\text { gende }\end{array}$ & & $\begin{array}{l}\text { Child } \\
\text { birth ranl }\end{array}$ \\
\hline \multirow{4}{*}{8 parents } & \multirow{4}{*}{33 years, } & \multirow{4}{*}{6 years, } & \multirow{2}{*}{ Mother } & \multirow{2}{*}{5} & $\begin{array}{l}\text { Middle } \\
\text { school }\end{array}$ & 2 & $\begin{array}{l}\text { Mother } \\
\text { employed }\end{array}$ & 1 & \multirow{2}{*}{$\begin{array}{l}\text { Single } \\
\text { child }\end{array}$} & \multirow{2}{*}{4} & \multirow{2}{*}{ Male } & \multirow{2}{*}{1} & \multirow{2}{*}{$\begin{array}{l}\text { First } \\
\text { child }\end{array}$} \\
\hline & & & & & Diploma & 4 & $\begin{array}{l}\text { House- } \\
\text { keeper }\end{array}$ & 4 & & & & & \\
\hline & & & \multirow{2}{*}{ Father } & \multirow{2}{*}{3} & $\begin{array}{c}\text { Associate } \\
\text { degree }\end{array}$ & 1 & $\begin{array}{l}\text { Father } \\
\text { worker }\end{array}$ & 1 & \multirow{2}{*}{$\begin{array}{l}\text { Two or } \\
\text { more }\end{array}$} & \multirow{2}{*}{4} & \multirow{2}{*}{ Female } & & \multirow{2}{*}{$\begin{array}{l}\text { Second } \\
\text { or more }\end{array}$} \\
\hline & & & & & $\begin{array}{l}\text { Master's } \\
\text { Degree }\end{array}$ & 1 & $\begin{array}{c}\text { Self- } \\
\text { employed }\end{array}$ & 2 & & & & 7 & \\
\hline
\end{tabular}

Table 3: Main and sub-categories extracted from the analysis of the experiences of parents with autistic children on their concerns about the future of the child

Main categories

Self-sufficiency and independency in life

Transition to adolescence sub-categories

Ambiguity of the future of the child, the ability of child to live in the society in the absence of parents, Child's future employment

Facing the physiological changes of puberty, Future social functioning

Child education and learning
Child's potential ability in learning, the educational system of accountability 


\section{Self-sufficiency and independency in life}

Self-sufficiency and independency in life, as one of the main categories of the research, was one of the most worrying issues about the future of the child referred to by most participants in their experiences. The analysis of the research data showed that the ambiguity of the child's future life, the ability of the child to live in society in the absence of parents, and Child's future employment, had caused a lot of psychological pressure on parents in raising their child. Meanwhile, the chronic and unknown nature of the disorder along with its debilitating symptoms and the perceived lack of support in the society, have prompted parents to be concerned about their child's future selfsufficiency and independency.

\section{"Ambiguity of the future of the child"}

The unknown, , vague and chronic nature of disorder and confusion of parents, as a result, the parents' perplexity over the child's raising has left the child's future in a state of ambiguity. One of the participants expressed about the ambiguous future of the child as a major concern affecting all aspects of family life as follows:

"Our concern (emphasis) is too much, what the future holds and what is going to happen (emphasis) has busied our lives and our minds ".(participant No.4)

Another participant expressed her negative perceptions about the ambigous future of her child:

" Our only problem is that my son is getting older and what will be his future?." (participant No.1)

\section{"The ability of the child to live in society in the absence of parents"}

The child independency in future life in the absence of parents, and the fear that the child will not be supported by the relatives in having a normal life, were concerns that the parents acknowledged in their experiences. One of the participants expressed her concern about the child's ability to have relative independency and a relatively simple and normal life in the absence of parents as follows:

"We are worried that if we were not here, later on, as we get older, could he be a normal and ordinary person to handle himself?. "(participant No. 3)

Another participant stated:

"I want him to only live in this society, defend his rights, to handle himself". (participantNo. 1)

One of the participants expressed his concern about the lack of emotional and financial support of the child from relatives in the absence of parents as follows:

"If this kid can't do the minimum of his life tomorrow, when we are not here, nobody will take care of him. Maybe if he can do minimum of his life, somebody will keep him, but if he can't, he can never have a normal life".(participant No.4)

One of the participants also described her fears and concerns about the child's independency and future rejection and its negative consequences:

"I ask from god that my son could participate in society, this rejection is so bad for him. The mental problems that he will have later is very bad. "(participant No. 7)

\section{"Child's future employment"}

The debilitating symptoms and the lack of professional support services for autism in the community has raised parental concerns about their child's future employment. One of the parents expressed her concern about the future employment of their child by expressing her expectations for support by the government as follows:

"I just expect the government to support these children. If my child was healthy, he would have worked for the government, but now that he is ill, shouldn't he work? ".(participant No. 6)

Lack of community support services as a cause of parental concern about the future employment of the child was mentioned by an autism expert as follows:

"Often teenagers in the autism spectrum need professional support and training in addition to family and friends support, and lack of professional services, lack of skilled professionals, unstable funding, and wrong public beliefs are key obstacles to obtaining professional services". ( Field note)

\section{Transition to adolescence}

Adolescence is the transition from childhood to adulthood and the most important event at this stage is puberty. Deficits in verbal, cognitive and social skills of the child with supportive problems in the society could cause problems in social functioning and exposure of the child to physiological changes of puberty, and could be a worrying factor for parents in portraying the child's future life in transition to adolescence.

\section{"Facing the physiological changes of puberty"}

The child's inability to express the needs due to interactive problems and a lack of understanding of social norms led to distressing negative thoughts about the child's puberty in some parents. The inability of the child to cope with the physiological changes of adolescence and the fear of care problems associated with it was the main concern of parents in transition to adolescence. One of the participants expressed concern about her child's inability to cope with the hormonal changes of her menstrual cycle and the issues related to it despite the complex and numerous problems of the child as follows:

"Since she has no urine and faeces control and wears diapers, think about the mensturation. You know how much trouble it is, how much this innocent child is suffering. How does this kid want to make me understand her problem? How many times this is going to happen? You go crazy when you think about it". (participant No.8)

Physiological changes in adolescence and related expected problems such as health and safety problems and the child's inability to cope, parents' inability to manage the problems, and the lack of adequate support in the community were the cause of parental concern on the eve of their children's puberty. 


\section{"Future social functioning"}

The child's social functioning in the area of cognitive skills and social actions was a cause of concern for parents in their child's transition to adolescence. An autism expert expressed parental concerns about the social functioning of the child in future life as follows:

"Transition to adolescence can be difficult for many teens and their parents. We have many concerns when our child reaches the adolescence. A teenager is having trouble in communication with others, understanding his emotional states, independent life, marriage, going to university, working, developing friendship networks and verbal reasoning." (Field note)

\section{Child's education and learning}

Most parents were concerned about the educational issues facing the child. The child's ability to learn, develop and benefiting the country's formal education system to gain empowerment and independence in the future, as well as the concern of institutions and educational systems of the country to have the capacity to respond to the educational needs of autistic children, in line with the fundamental philosophy of education of the country in the realization of educational justice, were the most challenging issues and worrying in the most participants, which are elaborated below:

\section{"Child's potential ability in learning"}

Participants' experiences indicated concerns about the child's learning and improvement ability and formal education in mainstream schools and the benefiting from community-based educational services along with peers for a better outcome for their child. One of the participants expressed her concern about the child's future learning and development as follows:

"I'm all worried about my son, will he be okay or not? Will he learn?." (participant No. 1)

Another participant expressed her concern about starting child's formal education by prioritizing education in mainstream schools as follows:

"Our concern is about school, that we hope she could go to a regular school ..." (participant No. 3)

\section{"Accountability of the education system"}

The special characteristic of children with autism, social rejection, cultural problems in society, and the lack of specific educational infrastructures for children with autism spectrum were the cause of parental concern about the educational system responding to future educational needs of their child.

Fear of rejection of the child in the mainstream schools due to the child's problematic behaviors and community ignorance was described by one of the participants based on their peer experiences as follows:

"The mom says when they call me from school and say why he doesn't answer when we call him, I don't know what to say. To put it bluntly, if say that my kid is autistic and accuse him, I will have to get him out of the regular school. So I have to handle it myself ". (participant No. 1)

An autism expert in the educational services explained the resistance of the educational system to accept children with autism spectrum in mainstream schools because of the social rejection of people with disabilities as follows:

"It's really hard to accept people who we feel they are a bit different with us in society. Usually the education system is very resistant to them and constantly tries to send these children to special school."(field notes)

Another participitant described her concern about the unresponsiveness of the educational system in acquiring the necessary abilities in her child to enter the society as follows:

"Now my kid is going to school (special school), he goes to the class, he has a workbook, he has a science book, does it help my kid to get into society?." (field Notes)

An autism expert expressed about the unresponsiveness of the country's educational system in terms of teaching social skills needed by children in the future life, as follows :

"We have little social skills training for our teenagers in our education systems right now. An autistic teenager needs these skills to get a job, make friends, have fun, have health and safety, manage his money, and maintain his status and so on."( field Note)

\section{Discussion}

Results of this study show the dimensions of parental concern about the future of the child with autism spectrum disorder, so that self-sufficiency and independency in life was one of the main categories extracted from the results of the present study. The analysis of the research findings showed that the ambiguity of the child's future, the ability to live in society in the absence of parents and future occupation were the main concerns of parents about the self sufficiency and independency of the child in future. Based on Nealy et al (2012) study, the ambiguity of the future living conditions of the child was a major concern of parents(19). Also the study findings of Ooi (2016), Herrema (2017) and Ogston et al. (2011) in agreement with the results of the present study showed that The ambiguity of the prognosis and the consequence of the disorder in terms of independence and achieving the most basic skills of survival and selfcare, as well as having a good quality of life, despite the growth retardation and dependence of the child on caregivers and poor growth and development of the child following interventions were the major concerns of parents regarding the child's well-being in the futher(10, 20, 21). In the present study, such conditions were more worrying when they were imagined the future life of the child in their absence. Also, The results of study Gobrial (2018) and Dababnah and Parish (2013), expressed parents' concerns about the transition of the child to adulthood and their inability to support her after death $(22,23)$. According to results of the study 
by Ludlow et .al (2011), coping of the child with the conditions after the death of the parents or their inability to take care of the child was one of the parents' concerns about the future well-being and independence of the child (24).

In the present study, fear of not being supported by relatives and the community in the absence of parents because of inadequate support services and resources was another aspect of parental concern. Based on Frye et al. (2015), and Minhas et al (2015) study, parents were concerned about treatment, misbehavior of the community, extended family, friends, educators, and treatment staff with children after their deaths . In fact, in agreement with the results of the present study, the lack of safe governmental welfare systems post-parental death and stigma associated with the disorder was a cause of parental concern $(25,26)$.

In the child's future perspective, parents were concerned about the child's professional performance, which is a prerequisite for self-sufficiency and independence. Consistent with the results of the present study, the study findings of Nealy et al. (2012) and Illias et al. (2017) showed that the employment status of the child due to inability to find a job and ambiguity about job opportunities for independence and self-support and thus the ability to adapt to Adulthood, along with a lack of supportive resources in society, was very worrying for parents $(19,27)$.

In the present study, a child's disability in developmental and social domains, along with supportive problems in society caused parental concern about the transition of the child to adolescence in the face of physiological changes of puberty and their social functioning, that was another major theme of the research. The results of study by Cummins et al. (2018) also showed that some parents experience anxiety before the onset of child puberty(28).

Based on Papageorgiou et al. (2010)study, parents of girls with autism spectrum disorder were more concerned with the problem of self-help skills especially during puberty and menstruation period(29), and in the study of Cummins et al. (2018), child's pain during the menstruation period, because of the child's inability to express it, raised concerns for mothers and educators in transition to puberty stage(28). However, parents of boys affected by autism spectrum disorder in the study by Papageorgiou et al. (2010) were more concerned about potential social problems that may lead to social rejection and legal problems(29).

According to the results of the present study, although boys with autism spectrum disorder were the majority, it seems that parents did not share their concerns about boys' puberty due to cultural considerations or shame. Also, the lack of necessary supportive resources and educational infrastructure in relation to the readiness of children and their families in transition to this stage of development and management of conditions was one of the causes of concern for parents of girls with autism spectrum disorder in the present study. However, the results of the study by Cummins et al. (2018) showed that parents and educators had positive experiences of girls puberty, such as menstrual management, promoting girls self-esteem, and supporting them during this growth period made them to adapt to physiological changes related to puberty(28).

Also in the present study, children's social functioning during transition to adulthood was one of the parents' concerns about the future life of the child. Also, the results of the study by Dababnah and Parish (2013) indicated parents' concern about their child's inability to receive a college education and marriage(23). Accordingly, given the constraints felt in providing services to children and their families in entering and managing this developmental stage, providing the necessary support by authorities of autism in country are especially important to ensure the wellbeing and empowerment of parents and their children in the successful transition to adulthood and responding to parental concerns.

Another aspect of parental concern about the child of future life and one of the main themes of the study was child learning and education, because it could prepare her/his for a better life in the future. Consistent with the results of the present study, the study findings of Raeis Dana et al. (2009), showed parental concerns about non-admission of their children in mainstream schools and child's education in future(30). In fact, in the present study, similar to the results of Bahir et.al. (2014) study, concern about a child's independence in future life due to lack of improvement despite following interventions was the concern of most parents of autistic children(31). In fact, formal child education in regular schools, like normal children, it gave parents more hope for the child's improvement and, consequently, her/his future.

The results of the present study, in agreement with the results of the study by Ahmadi et al. (2011), indicated lack of a specific educational curriculum for autistic children in response to their educational needs and having an independent life(32). Hemdi and Daley (2017) study also emphasized the educational needs of children with autism and the importance of education and learning for them(33). In fact, despite the efforts made by the Exceptional education organization as one of authorities of autism in country, these actions did not cover all the developmental stages of people with autism spectrum disorder, and therefore policy-making in the field of educational services of children with disabilities in all developmental stages, especially the transition to adulthood and meeting their educational needs in the emotional, social, and vocational areas, are increasingly felt.

Therefore, the present study, along with other available evidence, provides an opportunity to listen to the experiences of parents, especially in relation to their concerns with a child-centered perspective for future and based on family-centered care principles, to promote well-being children with autism spectrum disorder and their families have taken an effective step. Accordingly, informing the public about autism with emphasizing social acceptance, policy-making and organizing special educational services for children with autism in order to improve self-help skills, vocational 
training and social skills in transition to adulthood by the participation of family and related organizations; Creating suitable job opportunities for people with autism spectrum disorders through the participation of involved organizations such as the Ministry of Labor and Social Affairs; as well as providing adequate support resources in society, especially in the absence of parents and regulating inheritance and finance laws and supervising people with disabilities; in order to meet the needs of autistic children and their family, reducing the stress and worries of parents and thus maintaining and improving their well-being, are special priorities.

\section{Conclusion}

In this study, the parental concerns about the child's life in future are explained based on their experiences around the three axes of main categories of self-sufficiency and independency, transition to adolescence, and child education and learning. According to the results, , authorities and policy makers of autism in the country can be encouraged to design and implement effective interventions in educational, therapeutic, rehabilitation, welfare, legal and social areas appropriate to the child's developmental stages through awakening society about autism, respond to support needs especially in the successful transition to adulthood and promote well-being of children with autism and their families.

\section{Acknowledgments}

This study is part of the nursing Ph.D. thesis, which was permitted by the council of research of Ahvaz Jundishapur university of medical sciences with the code of ethics (ajums.REC.1393.8), and sponsored by the Ahvaz Jundishapur university of medical sciences. Hereby, the research team would like to appreciate the authorities and experts of Yas's rehabilitation center in Arak city and the Nahal rehabilitation center in Ahvaz, the welfare organization of Khuzestan and Markazi provinces for their cooperation in conducting this research.

\section{References}

1. Aali S, Yazdi SAA, Abdekhodaei MS, Chamanabad AG, Moharreri F. Developing a mixed familyfocused therapy based on integrated human development model and comparing its effectiveness with Floortime play-therapy on the developmental family functioning and the functional-emotional development of children with autism spectrum disorder. Journal of Funamentals of Mental Health 2015;17(2):87-97.

2. Dalvand H,Rassafiani M, Hosseini SA, Khankeh HR, Samadi SA. Co-occupations: An Open Window to the World of Caring of Children with Cerebral Palsy. Quarterly Journal of Rehabilitation 2014;14(6):8-17.

3. Estes A, Olson E, Sullivan K, Greenson J, Winter J, Dawson G, et al. Parenting-related stress and psychological distress in mothers of toddlers with autism spectrum disorders. Brain Dev 2013;35(2):133-8.

4. Craig F, Operto FF, De Giacomo A, Margari L, Frolli A, Conson M, et al. Parenting stress among parents of children with Neurodevelopmental Disorders. Psychiatry Res 2016;242:121-9.

5. Khoramabadi R, Pouretemad HR, Tahmasian K, Chimeh N. A comparative study of parental stress in mothers of autistic and non autistic children. Journal of Family Research 2009;5(3):387-389. (persian)

6. Khushabi K, Farzad Fard SZ, Kakasoltani B, Pouretemad HR, Nikkhah HR. Coping Strategies and Stress in Mothers with Autistic Children in Comparison with Mothers with Normal Children . Journal of Family Research 2010;6(1):87-97. (Persian)

7. McGrath P. Psycho-social issues in childhood autism rehabilitation: a review. International Journal of Psychosocial Rehabilitation. 2006;11(1):29-36.

8. Sun X, Allison C, Auyeung B, Baron-Cohen S, Brayne C. Parental concerns, socioeconomic status, and the risk of autism spectrum conditions in a population-based study. Research in Developmental Disabilities 2014;35(12):3678-88.

9. Magalhaes LS, Pereira AP.S. Early intervention in autism spectrum disorder: Concerns and support of Portuguese mothers. Education and Training in Autism and Developmental Disabilities 2017; 52(3): 240-51.

10. Ogston PL, Mackintosh VH, Myers BJ. Hope and worry in mothers of children with an autism spectrum disorder or Down syndrome. Research in Autism Spectrum Disorders 2011;5(4):1378-84.

11. Ogston PL. Hope and worry in mothers of children with an autism spectrum disorder or Down syndrome. Master of Science dissertation, Virginia Commonwealth University(2010).

12. Chan KKS, Lam CB, Law NCW, Cheung RYM. From child autistic symptoms to parental affective symptoms: A family process model. Research in developmental disabilities 2018;75:22-31.

13. Oprea C, Stan A. Mothers of Autistic Children. How do They Feel? Procedia - Social and Behavioral Sciences 2012;46:4191-4.

14. Saini M, Stoddart KP, Gibson M, Morris R, Barrett $\mathrm{D}$, Muskat B, et al. Couple relationships among parents of children and adolescents with Autism Spectrum Disorder: Findings from a scoping review of the literature. Research in Autism Spectrum Disorders 2015;17:142-57.

15. Soleimani H, Bashash L. Validation of the Revised Family Needs Survey (R-FNS) Scale for Families with Children with Special Needs. Knowledge \& Research in Applied Psychology 2014; 14(54): 106-20. (Persian)

16. Ilias K, Cornish K, Kummar AS, Park MS-A, Golden KJ. Parenting stress and resilience in parents of children with Autism Spectrum Disorder (ASD) in Southeast Asia: A systematic review. Frontiers in psychology 2018;9:280. 
Fatemeh Ganjeh et.al., Parental Concerns about the Future of Children with Autism: A Qualitative Study in Iran

17. Burns N, Grove SK . Understanding nursing research, building an evidence-based practice. $4^{\text {th }}$ ed. St. Louis: Saunders Elsevier; 2007.

18. Graneheim UH, Lundman B. Qualitative content analysis in nursing research: concepts, procedures and measures to achieve trustworthiness. Nurse education today 2004;24(2):105-12.

19. Nealy CE, O'Hare L, Powers JD, Swick DC. The impact of autism spectrum disorders on the family: A qualitative study of mothers' perspectives. Journal of Family Social Work 2012;15(3):187-201.

20. Ooi KL, Ong YS, Jacob SA, Khan TM. A metasynthesis on parenting a child with autism. Neuropsychiatric disease and treatment 2016;12:745.

21. Herrema R, Garland D, Osborne M, Freeston M, Honey E, Rodgers J. Brief report: What happens when I can no longer support my autistic relative? Worries about the future for family members of autistic adults. Journal of autism and developmental disorders 2017;47(11):3659-68.

22. Gobrial E. The lived experiences of mothers of children with the autism spectrum disorders in Egypt. Social Sciences 2018;7(8):133.

23. Dababnah S, Parish SL. "At a moment, you could collapse": Raising children with autism in the West Bank. Children and Youth Services Review 2013;35(10):1670-8.

24. Ludlow A, Skelly C, Rohleder P. Challenges faced by parents of children diagnosed with autism spectrum disorder. Journal of Health Psychology 2012;17(5):702-11.

25. Frye L. Fathers' Experience With Autism Spectrum Disorder: Nursing Implications. Journal of Pediatric Health Care 2015. (in press)

26. Minhas A, Vajaratkar V, Divan G, Hamdani SU, Leadbitter K, Taylor C, et al. Parents' perspectives on care of children with autistic spectrum disorder in South Asia-Views from Pakistan and India. International Review of Psychiatry 2015;27(3):247-56.

27. Ilias K, Liaw JHJ, Cornish K, Park MS-A, Golden KJ. Wellbeing of mothers of children with "AUTISM" in Malaysia: An interpretative phenomenological analysis study. Journal of Intellectual \& Developmental Disability 2017;42(1):74-89.

28. Cummins C, Pellicano E, Crane L. Supporting minimally verbal autistic girls with intellectual disabilities through puberty: perspectives of parents and educators. Journal of autism and developmental disorders 2018:1-10.

29. Papageorgiou V, Kalyva E. Self-reported needs and expectations of parents of children with autism spectrum disorders who participate in support groups. Research in Autism Spectrum Disorders 2010;4(4):653-60.

30. Raeis Dana M, Tabatabaei Nia M, Kamali M, Shafaroudi N. From Diagnosis to Coping: A Journey with Parents in the Course of the Disability of Their Children. Journal Of Rehabilitation 2009;10(1):42-51. (persian)

31. Bashir A, Bashir U, Lone A, Ahmad Z. Challenges faced by families of autistic children. International journal of interdisciplinary research and innovations 2014;2(1):64-8.

32. Ahmadi A, sharifi E, Zalani HA, bolouk S, Amrai $\mathrm{K}$. The needs of iranian families of children with autism spectrum disorder, cross-cultural study. Procedia - Social and Behavioral Sciences 2011;15:321-6.

33. Hemdi A, Daley D. The needs of mothers of children with autism spectrum disorder (ASD) in the Kingdom of Saudi Arabia (KSA): a qualitative study. International Journal of Academic Scientific Research 2017;5(3):19-29. 